\title{
A study of the phase transition behavior of internally mixed ammonium sulfate - malonic acid aerosols
}

\author{
C. F. Braban ${ }^{1}$ and J. P. D. Abbatt ${ }^{2}$ \\ ${ }^{1}$ Centre for Atmospheric Science, Dept. of Chemistry, Lensfield Road, University of Cambridge, Cambridge, CB2 1EW, UK \\ ${ }^{2}$ Department of Chemistry, University of Toronto, Toronto, ON, M5S 3H6, Canada
}

Received: 22 March 2004 - Published in Atmos. Chem. Phys. Discuss.: 2 June 2004

Revised: 23 August 2004 - Accepted: 25 August 2004 - Published: 1 September 2004

\begin{abstract}
This is a study into the phase transitions of aerosol composed of the ternary system ammonium sulfate (AS) malonic acid (MA) - water using infrared extinction spectroscopy. Twelve compositions were studied in both deliquescence and efflorescence mode experiments. The presence of a MA fraction, by dry mass, $\left(f_{\mathrm{MA}}\right)$ of 0.1 in an AS aerosol altered the relative humidity at which the phase transitions occur in an atmospherically significant manner. For compositions with $0.25<f_{\mathrm{MA}}<0.90$, no distinct "deliquescence" was observed, contrary to the observed behavior in the binary systems. The crystallization of both the MA and AS components is suppressed by the presence of the other component in the aerosol. At $f_{\mathrm{MA}}=0.9$, the crystallization relative humidity of MA was lowered from $\mathrm{RH}=6 \%$ to less than $1 \%$. Similarly, at $f_{\mathrm{MA}}=0.4$, the AS component did not crystallize. The atmospheric implications of the results are discussed.
\end{abstract}

\section{Introduction}

The phase of atmospheric aerosol particles is important when trying to determine the radiative balance of the atmosphere (IPCC 2001) as well as for chemical reactions occurring heterogeneously in the atmosphere (e.g. Ravishankara 1997). For example, $\mathrm{N}_{2} \mathrm{O}_{5}$ hydrolysis occurs heterogeneously on aerosol surfaces. This reaction has been shown to be a significant nighttime $\mathrm{NO}_{\mathrm{x}}$ sink and proceeds much more slowly on dry solid particles than on aqueous solution droplets, even if highly supersaturated (Mozurekewich and Calvert, 1988; Hu and Abbatt, 1997; Kane et al., 2001; Thornton et al., 2003). Hence, it is of great importance to understand phase transitions of atmospherically relevant aerosol under atmospheric conditions.

Correspondence to: J. P. D. Abbatt

(jabbatt@chem.utoronto.ca)
Ammonium sulfate (AS) is frequently used as a model tropospheric aerosol due to the widespread prevalence of ammonium and sulfate species in the troposphere. However, it has become evident that atmospheric aerosol is chemically more complex, with both organic and mixed inorganicorganic aerosols widely present in the troposphere. Several initial studies have focused on the properties of water-soluble organic compounds (WSOC) that are found in the atmosphere. Dicarboxylic acids, which have been identified globally in atmospheric aerosol (Narukawa et al., 1999; Rohrl and Lammel, 2001; Yao et al., 2002; Narukawa et al., 2002), have been considered by several recent phase transition studies (Prenni et al., 2001; Brooks et al., 2002; Braban et al., 2003; Marcolli et al., 2004; Parsons et al., 2004;).

Given the chemically mixed nature of aerosol, it is important to understand and quantify the effect of organic chemicals on the phase transition behavior of model inorganic tropospheric aerosols. To date several studies have considered mixtures of dicarboxylic acids and inorganic salts with respect to phase transitions or water uptake. Brooks et al. (2002) completed a study of the deliquescence relative humidities of ternary bulk solutions. Choi and Chan (2002) studied the water cycles of dicarboxylic acids with both sodium chloride and AS using an electrodynamic balance (EDB) technique. Three tandem differential mobility analyzer (DMA) studies have been performed. Cruz and Pandis (2000) studied mixtures of glutaric acid and AS. Prenni et al. (2003) studied the water uptake of AS-dicarboxylic acid mixtures at 3 compositions and Hameri et al. (2002) studied AS with several dicarboxylic acids. Wise et al. (2003) completed a detailed study of the water activity, phase transitions and growth of dicarboxylic acid-inorganic salt-water bulk solutions and aerosols. Marcolli et al. (2004) studied saturated bulk solutions of up to five dicarboxylic acids with ammonium nitrate, ammonium sulfate or sodium chloride. 


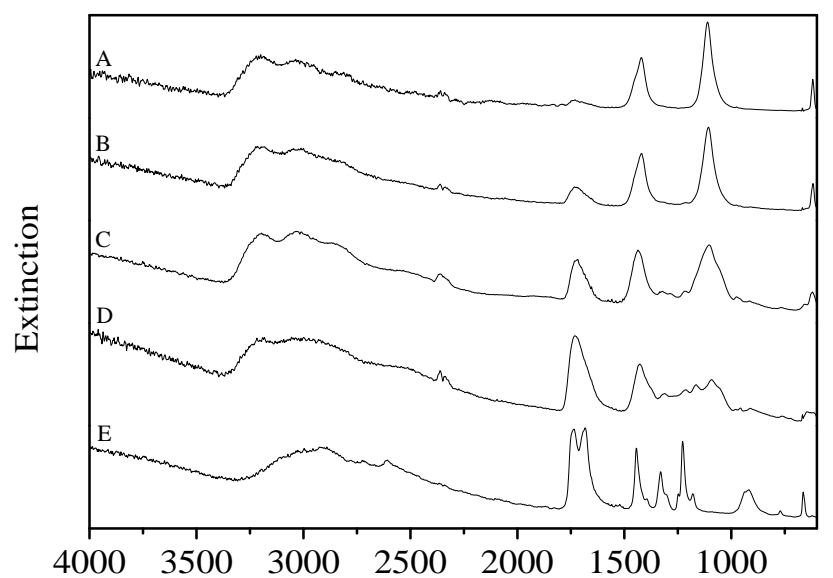

Wavenumber $\left(\mathrm{cm}^{-1}\right)$

Fig. 1. Infrared spectra of five compositions of ammonium sulfate (AS) - malonic acid (MA) solutions at $<1 \% R H$. Compositions as dry fraction of MA $\left(f_{\text {MA }}\right):$ A:0.10; B:0.25; C:0.49; D:0.75; E:0.90.

Using EDB, Lightstone et al. (2000) focused on the potential heterogeneous effect of succinic acid (SA) cores on the efflorescence $R H$ (ERH) of mixed ammonium nitrate - SA particles.

Though several studies have been performed, this work constitutes one of the first detailed case studies of ternary aerosol. The first was of the AS-maleic acid aerosol system (Brooks et al., 2003). Analysis of the results presented here and comparison with the literature noted above are used to more clearly understand the possible effects of WSOC on the phase transitions of atmospheric aerosol. In particular we focus on the effect of each species in solution on the phase transitions on the other. In our previous study (Braban et al., 2003) both MA and oxalic acid were observed to be stable as highly supersaturated solutions, therefore one immediate question was whether the presence of AS would inhibit or promote the crystallization of dicarboxylic acid particles. Conversely, would MA suppress the crystallization of AS? This is the first study to consider these processes in terms of the phase transitions of the individual components lending insight into the physical processes occurring and their relevance for atmospheric aerosol.

\section{Experimental}

The Aerosol Flow Tube - Fourier Transform-Infrared spectrometer system (AFT) used in this work has been previously described (Braban et al., 2003). Aerosol is produced using a commercial atomizer (TSI Model 3076). A fraction of the aerosol flow is discarded while the remainder either passes through a silica gel dryer (TSI 3062) or bypasses the dryer for the deliquescence and efflorescence experimental modes, respectively. The aerosol flow is mixed with a nitrogen flow,

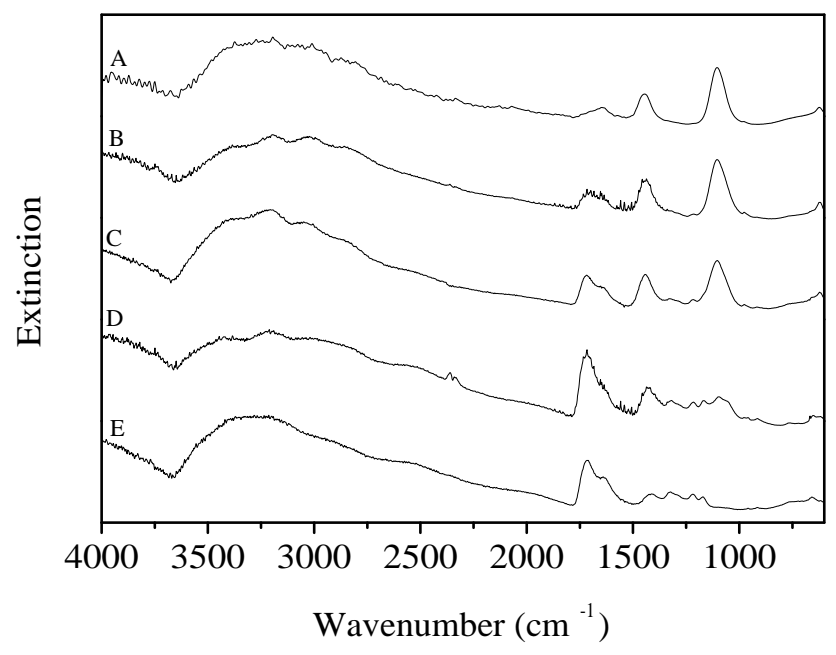

Fig. 2. Infrared spectra of five compositions of ammonium sulfate (AS) - malonic acid (MA) solutions at $>80 \% R H$. Compositions as dry fraction of MA $\left(f_{\mathrm{MA}}\right)$ : A:0.10; B:0.25; C:0.49; D:0.75; E:0.90.

a variable fraction of which is saturated with water vapor. In most experiments the total $\mathrm{N}_{2}$ flow was $21 \mathrm{~min}^{-1}$ though in some of the efflorescence mode experiments an additional $11 \mathrm{~min}^{-1}$ was added to study the low $R H$ range in more detail. The total flow $\left(2.3-3.31 \mathrm{~min}^{-1}\right)$ then passes through a precooler-mixing volume before entering the main aerosol flow tube.

Experiments are carried out by incrementally increasing or decreasing the $R H$ for deliquescence-mode or efflorescencemode experiments, respectively. Both the flow tube and the pre-cooler/mixer are temperature jacketed and controlled using a circulator (Julabo FP88-MW). The temperature in the flow tube is measured using two T-type thermocouples. The thermal gradient over the observation region is less than $0.2 \mathrm{~K}$ in all the experiments performed and generally less than $0.1 \mathrm{~K}$.

A length of $60 \mathrm{~cm}$ in the flow tube is monitored with the FTIR spectrometer (Bomem MB104). IR spectra are recorded over the wavenumber range $4000-500 \mathrm{~cm}^{-1}$ with a resolution of $4 \mathrm{~cm}^{-1}$. The $R H$ in the flow tube is measured using a gas-phase water line calibration, integrating the area under $1710 \mathrm{~cm}^{-1}-1690 \mathrm{~cm}^{-1}$ (Braban et al., 2003). The calibration was carried out in two ways: (i) by mixing of known flows of dry and water-saturated $\mathrm{N}_{2}$ at constant temperature; (ii) calibration using ice-saturated conditions between $213 \mathrm{~K}$ and $270 \mathrm{~K}$. In general, the confidence level of reported relative humidities is $\pm 1 \%$.

99.9\% assay AS (Fisher) and 99\% purity MA (SigmaAldrich Chemical Co.) were used to make the solutions. The percent dry mass composition of the solution was known. Compositions are described herein as the dry mass fraction of MA, $f_{\mathrm{MA}}$, i.e. $f_{\mathrm{MA}}=0.1$ represents $90 \% \mathrm{AS} / 10 \%$ MA. Infrared (IR) spectra were recorded as an average of 50 
scans. From the IR spectrum the $R H$ is measured using the gas phase water line calibration, as described above. The condensed-phase features of the aerosol IR spectrum are used to determine the phase state of the aerosol, and in particular the point at which phase transitions of the components occur.

\section{Results}

\subsection{Ammonium Sulfate + Malonic Acid Infrared Spectra}

In this study 12 solutions containing compositions between $100 \%$ AS and 100\% MA were studied. In Figs. 1 and 2, IR spectra for 5 compositions (A-E) of AS and MA are presented at $R H<1 \%$ and $R H>80 \%$, respectively. Gas phase water lines have been subtracted for clarity from the high $R H$ spectra. Compositions A-E shown in each figure are $f_{\mathrm{MA}}=0.10,0.25,0.49,0.75$ and 0.90 . The AS component of the aerosol will be considered first. In Fig. 1 and 2, spectrum A, absorption features are seen between $2800-3300 \mathrm{~cm}^{-1}$, $1420-1450 \mathrm{~cm}^{-1}, 1115 \mathrm{~cm}^{-1}$ and $620 \mathrm{~cm}^{-1}$ corresponding to $\mathrm{N}-\mathrm{H}$ stretch modes, $\mathrm{NH}_{4}^{+}$deformation mode and two sulfate bands, respectively (Cziczo and Abbatt 1999). These features are present as the fraction of MA is increased until $f_{\mathrm{MA}}=0.90$, where the AS features are not discernable. The $\mathrm{NH}_{4}^{+}$mode in Fig. 1a present at $1420 \mathrm{~cm}^{-1}$ is indicative of AS in the crystalline phase. The corresponding mode in Fig. $2 \mathrm{a}$ at $1455 \mathrm{~cm}^{-1}$ is indicative of the salt being in solution.

As the fraction of MA is increased changes are observed in the AS modes in the IR spectrum, specifically under the driest conditions (i.e. the spectra shown in Fig. 1, $R H<1 \%$ ) the AS modes are different from when $f_{\mathrm{MA}}>0.25$. When $f_{\mathrm{MA}}>0.25$, the $\mathrm{AS}$ modes are broader and the $\mathrm{NH}_{4}^{+}$mode at $1420 \mathrm{~cm}^{-1}$ is shifted to higher wavenumbers (seen in Fig. 1c and d) and there is also a side peak evident $\left(\sim 1050 \mathrm{~cm}^{-1}\right)$ on the broadened mode at $1105 \mathrm{~cm}^{-1}$. This is thought to be indicative of the AS component or a significant fraction of it, being aqueous rather than crystalline, i.e. at $R H<1 \%$ the AS component does not fully crystallize out. This will be more fully discussed in Sect. 3.2. In Fig. 2, the AS is clearly in the aqueous phase and the AS modes are broadened and decreased in intensity, with the AS mode shifted to $\sim 1450 \mathrm{~cm}^{-1}$. Condensed phase $\mathrm{H}_{2} \mathrm{O}$ features can be seen between $2500-3500 \mathrm{~cm}^{-1}, \sim 1600 \mathrm{~cm}^{-1}$ and $<1000 \mathrm{~cm}^{-1}$, being the $\mathrm{OH}$ stretch, the $\mathrm{H}-\mathrm{O}-\mathrm{H}$ bending mode and the $\mathrm{H}-$ bonding librations, respectively.

In considering the MA component of the aerosol, in Fig. 1a, the carbonyl stretch at $\sim 1720 \mathrm{~cm}^{-1}$ due to the MA is just observable. As the fraction of MA is increased, this mode increases in intensity and other IR features due to MA become apparent in the IR spectrum between 2000 and $1000 \mathrm{~cm}^{-1}$. In our previous aerosol studies, the carbonyl resolves into the two peaks at $1749 \mathrm{~cm}^{-1}$ and $1686 \mathrm{~cm}^{-1}$ when the MA is dry and crystalline (Braban et al., 2003). Also, features between 1500 and $1000 \mathrm{~cm}^{-1}$ are sharp and well resolved, and the modes at 912 and $630 \mathrm{~cm}^{-1}$ are present. The MA does not appear to be fully crystalline from the spectra at $R H<1 \%$, except at $f_{\mathrm{MA}}=0.90$ (Fig. 1e). It is thought that this is not due to the low intensity of the MA features in the spectra because in other experiments, not presented here, the two peaks of the carbonyl and the lower wavenumber modes were clearly resolvable if the MA was effloresced even at very low extinctions.

In a solution containing AS and MA it is possible other salts including ammonium bisulfate, letovicite and ammonium hydrogen malonate could form if partial dissociation of aqueous MA occurs (note that in a $6 \mathrm{M}$ aqueous solution of MA, $1.5 \%$ of the MA is in the form of the singly deprotonated malonate ion $\mathrm{MA}^{-}$; this fraction increases as the solution becomes more dilute. In $0.1 \mathrm{M}, 10 \%$ of the MA is dissociated). The side-peak at $1050 \mathrm{~cm}^{-1}$ in Fig. $1 \mathrm{c}$ and $\mathrm{d}$ is at the same position as a bisulfate mode (Cziczo and Abbatt, 2000), however the most intense peak indicative of bisulfate at $1200 \mathrm{~cm}^{-1}$ is notably absent. It is thought that this shoulder is mostly broadening of the AS mode due to dissolution alone. It is possible that some letivocite $\left(\left(\mathrm{NH}_{4}\right)_{3} \mathrm{H}\left(\mathrm{SO}_{4}\right)_{2}\right)$ may have formed given that there are apparent shoulders at $1210 \mathrm{~cm}^{-1}$ and $1095 \mathrm{~cm}^{-1}$. The evidence against the presence of large amounts of letovicite in the particles is the absence in Fig. 1c of a strong peak between 1500 and $1600 \mathrm{~cm}^{-1}$ which is present in spectra of ammonium malonate and bimalonate particles (Charbonnier and Arnaud, 1973; Braban and Abbatt, in preparation ${ }^{1}$ ). Also, the absence of weak-to-medium strength peaks at close to $880 \mathrm{~cm}^{-1}$ that are characteristic of letovicite (Schenkler et al., 2004; Scot Martin, private communication) is noted. Given the evidence to date, we believe that small amounts of letovicite may indeed have formed but it is likely to be a minor fraction. In support of this we also note that in x-ray diffraction experiments which are detailed in a forthcoming paper (Braban and Abbatt, in preparation ${ }^{1}$ ) low levels of letovicite were observed in dry particles in which a small fraction of malonic acid was present with ammonium sulfate. Therefore, observations imply that ammonium bisulfate, letovicite or ammoniated malonate species when present, are at very low levels below our IR detection limit of a few weight percent.

\subsection{Analysis of Phase Transitions}

For each composition, both an efflorescence mode and a deliquescence mode experiment were performed at $283 \mathrm{~K}$ and $293 \mathrm{~K}$, respectively. In binary solutions (i.e. $\mathrm{A}+\mathrm{H}_{2} \mathrm{O}$ ), if a particle is dry, deliquescence is generally observed at the thermodynamically predicted deliquescence $R H$. Similarly for a ternary solution (i.e. $\mathrm{A}+\mathrm{B}+\mathrm{H}_{2} \mathrm{O}$ ) the lowest $R H$ at which the solution is in equilibrium with solid components $\mathrm{A}$

\footnotetext{
${ }^{1}$ Braban, C. F. and Abbatt, J. P. D.: Phase Transitions of Multicomponent Aerosols, Atmos. Chem. Phys., in preparation, 2004.
} 


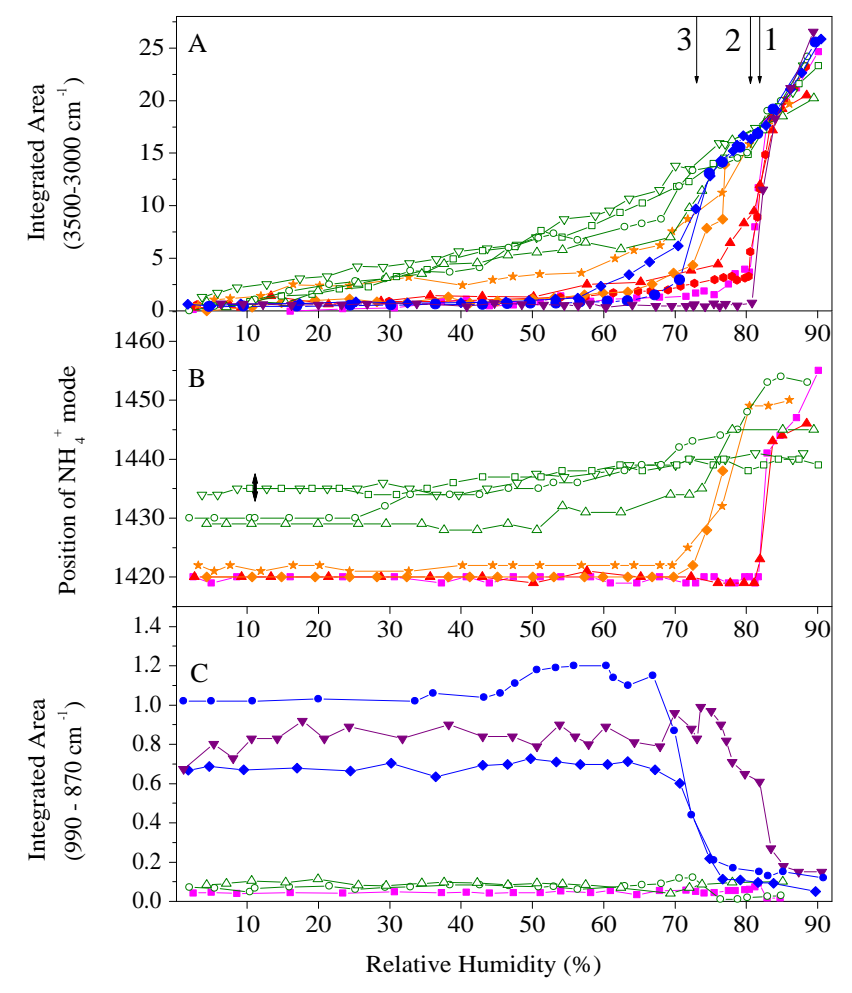

Fig. 3. Deliquescence Mode Experiments. (a) Integrated Area (3500-3000 $\mathrm{cm}^{-1}$ ) due to condensed phase water as a function of $R H$. (b) Position of ammonium mode $\left(\mathrm{NH}_{4}^{+}\right)$. (c) Integrated area of malonic acid mode between $990-870 \mathrm{~cm}^{-1}$. Composition key: $f_{\text {MA }}$ (symbol): 0.00 (pink $\square$ ); 0.01 (red filled hexagon); 0.06 (red filled $\triangle$ ); 0.10 (orange filled $\diamond$ ); 0.25 (orange filled star); 0.40 (green $\nabla$ ); 0.49 (green $\square$ ); 0.60 (green $\bigcirc$ ); 0.75 (green $\triangle$ ); 0.92 (blue filled $\diamond$ ); 0.98 (blue filled $\bigcirc$ ); 1.00 (purple filled $\nabla$ ). Arrows: 1: $\mathrm{DRH}_{\mathrm{AS}} ; 2: \mathrm{DRH}_{\mathrm{MA}} ; 3: \mathrm{EDRH} ; \mathfrak{\uparrow}$ : Uncertainty in peak position resolution.

and B (in this case AS and MA) can be calculated (Seinfeld and Pandis, 1998) and measured. This invariant point of the ternary system is called the eutonic deliquescence $R H$ (EDRH). Brooks et al. (2002) measured the EDRH for the AS-MA ternary system with bulk solutions as a function of temperature. Deliquescence mode experiments presented here were performed at $283 \mathrm{~K}$ to differentiate between the binary deliquescence processes, which occur at $283 \mathrm{~K}$ at $R H$ $\sim 81 \%$, and the predicted EDRH at $R H=72 \%$, with an estimated error of $\pm 2 \%$. It is noted that letovicite deliquesces at $69.5 \%$, therefore it would not be possible to differentiate between the eutonic transition and letovicite transition.

To understand the phase of both the AS and MA components of the aerosol particles, the IR spectra were analyzed as a function of $R H$. In aerosol IR spectra there are 2 main types of features that may be analyzed to understand the phase of that component: the presence of condensed phase $\mathrm{H}_{2} \mathrm{O}$ and the IR features of the salt/acid. In previous studies the integrated area due to the $\mathrm{OH}$ stretch of condensed

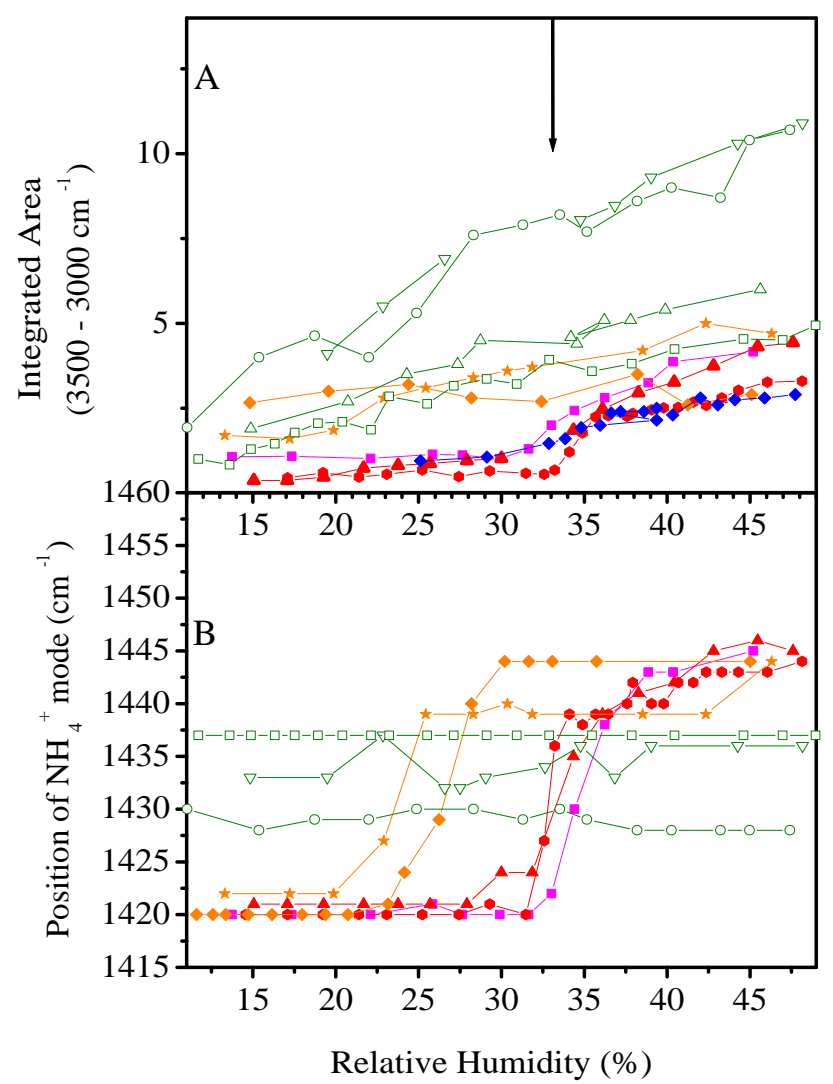

Fig. 4. Efflorescence mode experiments. (a) Integrated area (3500$3000 \mathrm{~cm}^{-1}$ ) due to condensed phase water as a function of $R H$. (b) Position of ammonium mode $\left(\mathrm{NH}_{4}^{+}\right)$. Composition key: $f_{M A}$ (symbol): 0.00 (pink $\mathbf{\square}$ ); 0.01 (red filled hexagon); 0.06 (red filled $\triangle) ; 0.10$ (orange filled $\diamond) ; 0.25$ (orange filled star); 0.40 (green $\nabla$ ); 0.49 (green $\square$ ); 0.60 (green $\bigcirc$ ); 0.75 (green $\triangle$ ); 0.92 (blue filled $\diamond)$; Arrow: $\downarrow$ : $\mathrm{ERH}_{\mathrm{AS}}$.

phase water has been used for this purpose. For example, in our previous study (Braban et al., 2003) the area under $3500-3000 \mathrm{~cm}^{-1}\left(\mathrm{~A}_{\mathrm{H}_{2} \mathrm{O}}\right)$, after the subtraction of the lowest $R H$ spectrum, was used to analyze for the presence of condensed phase water. To account for differences in the aerosol populations used in different experiments the integrated area $\mathrm{A}_{\mathrm{H}_{2} \mathrm{O}}$ was normalized to the integrated area at $R H=83 \%$, at which point all aerosols were aqueous. This process did not alter any of the major features, but allowed greater clarity in observing the differences in the experimental results. For clarity the efflorescence and deliquescence experiments were shown on separate figures. The integrated areas are different for the experiments presented in Figs. 2 and 3 because they were normalized at different relative humidities so that comparison between the different compositions in that particular mode of experiment could be facilitated.

Brooks et al. (2003) used a ratio method to study phase transitions in the ternary AS-maleic acid- $\mathrm{H}_{2} \mathrm{O}$ system, using both the condensed phase water and acid modes. In the 
Table 1. Summary of Observations.

\begin{tabular}{llllll}
\hline & \multicolumn{2}{c}{ AS } & \multicolumn{2}{c}{ MA } & Significant \\
$f_{\mathrm{MA}}$ & Deliquescence & Crystallization & Deliquescence & Crystallization & $\mathrm{H}_{2}$ O Uptake \\
\hline 0 & Yes & Yes & - & - & $R H>81 \%$ \\
$0.02-0.1$ & Yes & Yes & - & - & $R H>81 \%$ \\
0.1 & Yes & Yes & No & No & $R H>73 \%$ \\
0.25 & Yes & Yes & No & No & $R H>73 \%$ \\
0.40 & Dissolution & Partial $^{2}$ & No & No & All $R H$ \\
0.5 & No & No & No & No & All $R H$ \\
0.60 & Dissolution & Partial & No & No & All $R H$ \\
0.75 & Dissolution & Partial & No & No & All $R H$ \\
$>0.90$ & - & - & No & No & $R H>73 \%$ \\
1 & - & - & Yes & Yes & $R H>81 \%$ \\
\hline
\end{tabular}

${ }^{1}$ Full AS crystallization has not occurred. Potentially AS dissolves in supersaturated solution as $R H$ increases.

${ }^{2}$ Full AS crystallization has not occurred.

present work, in addition to the condensed phase water, we have analyzed the phase transitions of AS and MA IR features. The AS mode at $1420 / 1455 \mathrm{~cm}^{-1}$ shifts upon dissolution as discussed in Sect. 3.1. The results from the condensed phase water and AS mode analyses of deliquescence and efflorescence mode experiments are presented in Figs. 3 and 4 respectively. For clarity not all compositions are shown in every figure. In Figs. $3 \mathrm{a}$ and $4 \mathrm{a}$, the normalized $\mathrm{A}_{\mathrm{H}_{2} \mathrm{O}}$ is plotted as a function of $R H$. In Figs. $3 \mathrm{~b}$ and $4 \mathrm{~b}$, the position of the $\mathrm{NH}_{4}^{+}$mode is plotted as a function of $R H$. The vertical arrows in Fig. 3 represent the DRH of MA (DRH MA $_{\text {, }}$ Arrow 1), AS (DRH $\mathrm{DS}_{\mathrm{S}}$, Arrow 2) and the EDRH for an ASMA solution (Arrow 3; Brooks et al., 2002). To quantify the phase transitions of MA, it can be seen that the mode at $665 \mathrm{~cm}^{-1}$ changes intensity and the broad mode at $918 \mathrm{~cm}^{-1}$ decreases greatly in intensity when MA becomes aqueous. Both of these features were used to analyze the phase of the MA. The results from the latter analysis for deliquescence mode experiments are shown in Fig. 3c.

The results presented in Figs. 3-5 are discussed below using composition classification based on the observed behavior. In particular, results have been color coded with respect to the phase transition behavior of AS. In Fig. 3b, the blue double-ended arrow indicated the $\pm 4 \mathrm{~cm}^{-1}$ resolution used in these experiments. The results and observations are summarized in Table 1.

\subsubsection{Results: $0 \leq f_{\mathrm{MA}}<0.10$ (pink and red symbols)}

AS aerosol (Fig. 3), take up very little $\mathrm{H}_{2} \mathrm{O}, \mathrm{A}_{\mathrm{H}_{2} \mathrm{O}} \sim 0$, as $R H$ increases until the DRH is reached, measured here as $R H=81 \pm 2 \%$. This value is in agreement with previously measured values (Xu et al., 1998; Cziczo and Abbatt, 1999; Onasch et al., 1999; Braban et al., 2001). Similarly, in the efflorescence experiment (Fig. 4), $\mathrm{A}_{\mathrm{H}_{2} \mathrm{O}}$ decreases as $R H$ is lowered. At $R H=33 \pm 2 \%, \mathrm{~A}_{\mathrm{H}_{2} \mathrm{O}}$ decreases to a small and ap- proximately constant value when efflorescence occurs. This $R H$ is also consistent with other studies (Cziczo and Abbatt, 1999). Deliquescence and efflorescence are also seen clearly in the shift of the $\mathrm{NH}_{4}^{+}$mode in Figs. $3 \mathrm{~b}$ and $4 \mathrm{~b}$.

In deliquescence mode when there is a very minor fraction of MA present in the aerosol particles, $f_{\mathrm{MA}}=0.01$ and 0.06 , there is an increase in $\mathrm{A}_{\mathrm{H}_{2} \mathrm{O}}$ with $R H$ even when the $R H<\mathrm{DRH}_{\mathrm{AS}}$, though the amount of condensed phase water is small. From the analysis of the ammonium mode, the AS component is crystalline at all $R H<\mathrm{DRH}_{\mathrm{AS}}$ and at $\mathrm{DRH}_{\mathrm{AS}}$ the ammonium mode shifts to $\sim 1450 \mathrm{~cm}^{-1}$, indicating deliquescence of the ammonium sulfate. It is not possible to analyze the MA mode at $912 \mathrm{~cm}^{-1}$ due to the minor fractions of MA. Qualitatively, from the observation of the carbonyl mode discussed in Sect. 3.1 and the observation of a small increase of condensed phase water as a function of $R H$ we believe that the MA does not appear to be crystalline at $R H<\mathrm{DRH}_{\mathrm{AS}}$. However we also note that this increase may be due to the presence of adsorbed water at higher $R H \mathrm{~s}$, given that a small amount of water uptake is observed before deliquescence in the single component AS aerosol. These results will be further discussed in Sect. 4. In efflorescence experiments aerosol crystallized at the ERH of pure AS, to within the error of the experiments.

\subsubsection{Results: $0.10 \leq f_{\mathrm{MA}} \leq 0.25$ (orange symbols)}

The deliquescence-mode experiments for the composition range $0.10 \leq f_{\mathrm{MA}} \leq 0.25$ are presented as orange symbols in Fig. 3. Water uptake occurs over the complete $R H$ range. However the major increase in $\mathrm{A}_{\mathrm{H}_{2} \mathrm{O}}$ occurs close to the EDRH for the AS-MA system at this temperature (Brooks et al., 2002). This observation is consistent with the shift in the $\mathrm{NH}_{4}^{+}$mode which also occurs at approximately $73 \% \mathrm{RH}$ for both the $f_{\mathrm{MA}}=0.10$ and 0.25 . In Figs. 2 and 3 the transition between the dry AS peak position and the aqueous position 
does occur more gradually than in the pure AS experiment (over a range of $\sim 5 \% R H$ ), suggesting that dissolution is occurring. However, the two peaks are not well-resolved. One potential approach would be to use a fitting procedure involving two overlapping peaks. This might be able to deconvolute the two phases, but was not attempted as part of this study. There is insufficient MA to analyze the phase of the MA quantitatively, however there is water uptake at all relative humidities and, qualitatively, from the IR spectra the MA does not appear to be fully dry. Thus, it is thought that the "dry" aerosol $(R H<1 \%)$ used in the deliquescence mode experiments consists of solid AS with some supersaturated solution of MA.

In efflorescence mode experiments, it can be seen from both the $\mathrm{A}_{\mathrm{H}_{2} \mathrm{O}}$ and the $\mathrm{NH}_{4}^{+}$plot (Figs. 4a and b) that the crystallization of AS in these aerosols is significantly lowered compared to that of pure AS. This process is not full efflorescence as there is still condensed phase water associated with the aerosol, therefore the term crystallization is used to describe the phase transition of the AS component of the aerosol.

\subsubsection{Results: $0.25<f_{\mathrm{MA}} \leq 0.90$ (green symbols)}

For compositions $0.25<f_{\mathrm{MA}} \leq 0.90$ water uptake occurs at all relative humidities in deliquescence-mode experiments and there is little hysteresis in the $\mathrm{A}_{\mathrm{H}_{2} \mathrm{O}}$ plots between the efflorescence and deliquescence mode experiments (Figs. 3a and 4a). This is consistent with the IR spectra in Figs. 1b, c and $\mathrm{d}$ being similar to the equivalent spectra in Fig. 2 and also with neither component of the aerosol having fully crystallized. This observation is confirmed by virtually no abrupt shift in the $\mathrm{NH}_{4}^{+}$mode (Fig. 3b) for compositions $f_{\mathrm{MA}}=0.40$ and 0.50. It is thought that this is not due to any masking of the shift by the presence of the MA mode at $1444 \mathrm{~cm}^{-1}$, as one would still see a significant shift at the DRH or EDRH particularly when AS is the major fraction. For these compositions however it is noted that there is a gradual shift in this mode to slightly higher wavenumbers as $R H$ increases. It could be argued that $f_{\mathrm{MA}}=0.75$ has a considerable shift in wavenumber at the EDRH, however this shift initiates at about $50 \% R H$, quite unlike the behavior of particles with a lower $f_{\mathrm{MA}}$ (e.g. $f_{\mathrm{MA}}=0.25$ ). In Table 1 , the AS transitions of $f_{\mathrm{MA}}=0.40,0.60$ and 0.75 have been categorized as "partial" crystallization in efflorescence-mode experiments and "dissolution" in deliquescence-mode. Possible reasons why these processes might occur will be discussed in Sect. 4.

\subsubsection{Compositions: $0.90<f_{\mathrm{MA}} \leq 1.00$ (blue and purple symbols)}

Deliquescence mode experiments for both $f_{\mathrm{MA}}=0.92$ and 0.98 show a small amount of water uptake prior to deliquescence at the EDRH. Although there is too little AS present to study the position of the $\mathrm{NH}_{4}^{+}$mode, in Fig. 3c the MA mode at $923 \mathrm{~cm}^{-1}$ is plotted as a function of $R H$. In deliquescence-mode experiments, after the aerosol is exposed to the silica dryer and mixed with $21 \min ^{-1} \mathrm{~N}_{2}$, the initial $R H$ is less than $1 \%$. The MA appears crystalline until the major water uptake and deliquescence occurs at the EDRH, however there still seems to be some water uptake at $R H<$ EDRH. Also, there is some loss of peak area before the water is seen in the condensed phase in the pure MA aerosol.

The similar analyses of the MA mode described above and shown in Fig. 3c were performed for the efflorescence mode experiments presented in Fig. 4. Only in the case of pure MA was efflorescence observed at 6\% RH (Braban et al., 2003). For clarity the data are not shown in a third panel in Fig. 4. However to emphasize, no changes in the IR were observed in any of the MA modes during efflorescence mode experiments. The minimum $R H$ attainable in efflorescence-mode is approximately $3 \%$, thus this implies that MA efflorescence has been lowered to below this value.

In summary, for compositions $f_{\mathrm{MA}}=0.92$ and 0.98 , aerosols were observed to deliquesce at the EDRH, with some $\mathrm{H}_{2} \mathrm{O}$ uptake prior to it. Efflorescence was not quantitatively observed for either component in these experiments as it was not possible to observe the AS modes. In efflorescence experiments MA clearly did not crystallize implying the addition of even low levels of AS suppresses the efflorescence of MA to $<3 \% R H$.

\section{Discussion and Atmospheric Implications}

\subsection{Summary of Results}

Experiments have been performed with the AFT to identify phase transitions of aerosol composed of AS, MA and $\mathrm{H}_{2} \mathrm{O}$. The results for the AS and MA phase transitions and the water uptake characteristics are described in Table 1. When $f_{\mathrm{MA}}<0.1$, phase transitions occurred at the $\mathrm{DRH}_{\mathrm{AS}}$ and $\mathrm{ERH}_{\mathrm{AS}}$. However between $0.1<f_{\mathrm{MA}}<0.25$ deliquescence commenced at the eutonic DRH for the AS-MA system and the crystallization $R H$ of AS was lowered. The crystallization $R H$ of $\mathrm{MA}$ was $<3 \%$ when any AS was present. When $f_{\mathrm{MA}}>0.25$, AS did not crystallize even when $R H<1 \%$. The onset of deliquescence is fairly clear for compositions in which either MA or AS are the minor components $\left(f_{\mathrm{MA}} \leq 0.25\right.$ and $f_{\mathrm{MA}} \geq 0.9$. However due to the large changes in the IR, in particular the broadening of most of the modes and the change in scattering as a function of $R H$, it is not possible to state the end of deliquescence with much certainty. In general, it appears as though all systems have fully deliquesced by at least $82 \% R H$, if not at a somewhat lower $R H$.

To follow the AS phase transitions occurring, in Fig. 5 the $\mathrm{RH}$ at which the $\mathrm{NH}_{4}^{+}$mode is observed to start to shift as a function of $R H$ has been plotted for the different aerosol compositions. That MA suppresses the crystallization of 
the AS is clearly seen, implying that in the atmosphere this would allow the particles to remain as a metastable supersaturated solution to low relative humidities. It is noted that the remaining supersaturated solution may be acidic in nature if a small amount of letovicite formation has occurred. Between $0.25<f_{\mathrm{MA}}<0.90$, no distinct deliquescence or efflorescence was observed, with particles taking up water at all relative humidities. In this composition range, AS did not appear to fully crystallize even when $R H<1 \%$. In summary, it only requires a very low level of AS or MA to shift the starting point of deliquescence to the EDRH. Full crystallization of $\mathrm{MA}$ and AS is suppressed by the presence of the other component. If there is a significant AS and MA fraction, water uptake occurs at all relative humidities. This behavior, should it be widely applicable, will have a large impact on the phase of chemically mixed aerosol in the atmosphere.

The lowering of the deliquescence $R H$ of AS, initially to the eutonic $R H$, is also clear. We have included in Fig. 5 the points at which the $\mathrm{NH}_{4}^{+}$mode begins to shift in deliquescence mode experiments where it is thought that full AS crystallization has not occurred. Two hypotheses are suggested as to why the $\mathrm{NH}_{4}^{+}$mode should shift in such a way. First, it is possible a fraction of the AS has crystallized (as the aerosol is taken to a lower $R H$ in deliquescence mode experiments compared to the efflorescence mode experiments). If so, the shift may be due to a solubility of AS in supersaturated MA solution. The second hypothesis is that the AS/MA supersaturated solution chemical environment changes as a function of $R H$, such that the $\mathrm{NH}_{4}^{+}$mode shifts. At this stage it is not possible to verify either hypothesis.

\section{Comparison with other literature and atmospheric implications}

Ternary AS-MA- $\mathrm{H}_{2} \mathrm{O}$ aerosols have been studied by three other groups (Hameri et al., 2002; Choi and Chan, 2002; Prenni et al., 2003). In the first two of the studies a 1:1 mixture (by mass and by mole, respectively) was studied and water uptake at all relative humidities was observed, which is supported by the results presented herein. Of these, Hameri et al. (2002) noted that the deliquescence of AS was not visible indicating that the deliquescence properties of the ASMA particles are completely different to that of pure AS. Choi and Chan (2002), whose experiments were performed with an EDB, reported a crystallization $R H$ of $45.9-46.9 \%$ and a deliquescence $R H$ range of $57.8-73.7 \%$ (at $298 \mathrm{~K}$ ), noting that the particles absorb a significant amount of water before the DRH. However, it is not clear that the entire particle crystallizes at the reported ERH, as water is still present below $R H=45 \%$ even to very low relative humidities. If the observations of this study are taken into account, it seems likely that the particle may have partially crystallized. Differences in efflorescence relative humidities between EDB and AFT experiments have been noted, as the particles in EBD

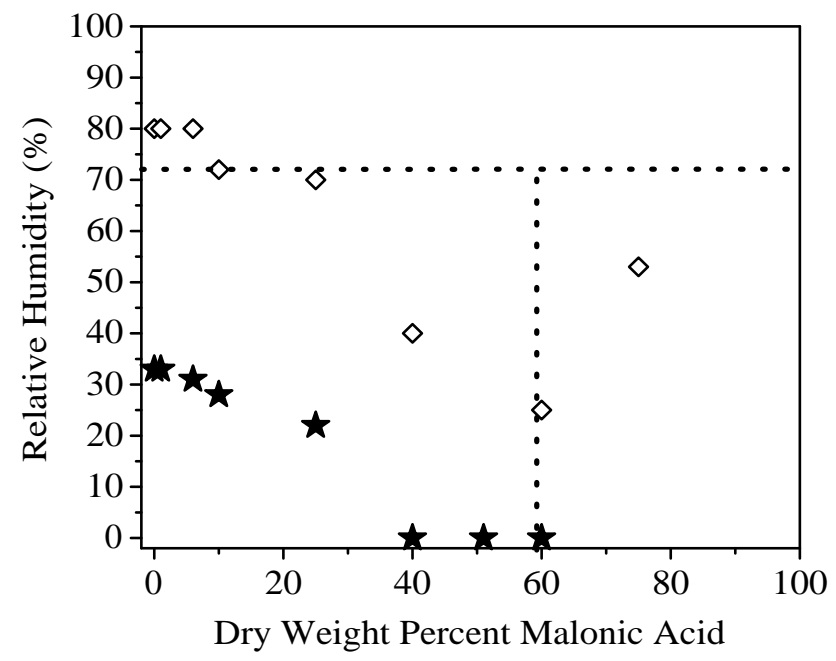

Fig. 5. Phase transition points of ammonium sulfate in ammonium sulfate-malonic acid mixtures as determined by shift in $\mathrm{NH}_{4}^{+}$mode: Ammonium sulfate observed to go into solution, $283 \mathrm{~K}$ (open diamonds); Crystallization of ammonium sulfate, $293 \mathrm{~K}$ (black filled stars). Eutonic composition and EDRH for ammonium sulfate malonic acid $-\mathrm{H}_{2} \mathrm{O}$ ternary system at $283 \mathrm{~K}$ is shown with the dashed line (Brooks et al., 2002). See text for details.

studies are significantly larger than those in tandem DMA and AFT experiments. EDB results can give a higher ERH than AFT experiments, which can possibly be attributed to the larger size of the particles, the volume based probability of a crystal embryo and longer residence time allowing mass transfer limited processes to occur. However, in order to systematically compare the results from the different experimental techniques it has been suggested that it would be relevant to calculate the relative nucleation rates and the supersaturation of the solutions at crystallization (A. Bertram, private communication). Prenni et al. (2003) with AS:MA ratios of 100:1 and 10:1 observed no effect on the AS phase transition. With a ratio 2.3:1 the particles showed continuous water absorption at all relative humidities was observed, which is in agreement with this study.

As mentioned previously, Brooks et al. (2003) investigated the AS-maleic acid- $\mathrm{H}_{2} \mathrm{O}$ ternary aerosol system in a study analogous to this. Similar to MA, maleic acid is highly soluble. The internally mixed AS-maleic acid particles deliquesced at a lower $R H$ than either of the single component systems, consistent with this study. In efflorescence studies they observed maleic acid ERH of $17 \%$ at $273 \mathrm{~K}$ and mixed aerosols effloresced at $27 \pm 3 \% R H$, which implied the maleic acid was heterogeneously crystallized by the AS, in contrast to the suppression of the ERH that we observe. Both studies conclude that the presence of water-soluble organics internally mixed with AS aerosol could increase the range of conditions under which aerosol is in a solution phase. 
The behaviour observed in this study may have significant atmospheric relevance. It is clear from this work and other studies that MA can inhibit the crystallization of AS. Other chemical systems have been observed to behave similarly. Prenni et al. (2003) and Marcolli et al. (2004) have demonstrated that increased chemical complexity can potentially lower the DRH such that a particle could exist in a supersaturated liquid state. It can be seen that the AS also does not promote the heterogeneous nucleation of MA aerosol, even when present as a major fraction of the aerosol. This behavior is in contrast to several studies that have investigated heterogeneous nucleation in aerosol particles, including Lightstone et al. (2000) and Martin et al. (2001). If sufficiently large nuclei of a solid are present, that solid has the potential to act as a heterogeneous nucleus. However, whether the process will occur frequently is dependant on the chemical nature of the system and the size of the inclusion. Lightstone et al. (2000) studied deliquescence, efflorescence and water activity in mixed ammonium nitrate-succinic acid$\mathrm{H}_{2} \mathrm{O}$ particles in which both the presence of solid inclusions of succinic acid and fully dissolved succinic acid were investigated. Ammonium nitrate particles do not effloresce down to $\sim 0 \% R H$ whereas Lightstone et al. found that the presence of an SA core increased the ERH of AN. Similarly, it has been shown in studies of particles with inorganic "refractory" inclusions that efflorescence may be catalyzed, i.e., heterogeneous nucleation occurs (Han and Martin, 1999; Martin et al., 2001). In the experiments presented here, AS does not act as a heterogeneous crystallization site for the MA. This is possibly due to the barrier to nucleation of MA crystals or the presence of residual AS in the supersaturated solution fraction of the droplet adds an extra barrier to the formation of critical embryonic crystals of MA.

In summary, this study has shown that in order to gain understanding of phase transitions in mixed phase systems it is necessary to identify the individual species that crystallize and those that remain in solution, as it is somewhat ambiguous to refer to deliquescence and efflorescence. The AS-MA$\mathrm{H}_{2} \mathrm{O}$ system shows a range of behaviors, as summarized in Table 1, most of which include significant water uptake at all atmospheric relative humidities and lack of full efflorescence. Therefore, in the absence of heterogeneous nuclei, it is likely the particles would exist as either saturated or supersaturated, potentially partially crystallized, droplets under most conditions.

Acknowledgements. The authors would like to acknowledge NSERC and CFCAS for partial financial support and A. Bertram, S. Martin and the anonymous referees for highly constructive comments on this work.

Edited by: M. Ammann

\section{References}

Braban, C. F., Carroll, M. F., Styler, S. A., and Abbatt, J. P. D.: Phase transitions of malonic and oxalic acid aerosols, J. Phys. Chem. A, 107, 6594-6602, 2003.

Braban, C. F., Cziczo, D. J., and Abbatt, J. P. D.: Deliquescence of ammonium sulfate particles at sub-eutectic temperatures, Geophys. Res. Lett., 28, 3879-3882, 2001.

Brooks, S. D., Garland, R. M., Wise, M. E., Prenni, A. J., Cushing, M., Hewitt, E., and Tolbert, M. A.: Phase changes in internally mixed maleic acid/ammonium sulfate aerosols, J. Geophys. Res., 108, 4487, doi:10.1029/2002JD003204, 2003.

Brooks, S. D., Wise, M. E., Cushing, M., and Tolbert, M. A.: Deliquescence behavior of organic/ammonium sulfate aerosol, Geophys. Res. Lett., 29, 1917, doi:10.1029/2002GL014733, 2002.

Charbonnier, F. and Arnaud, Y.: Etude par diffraction X et analyse thermique du malonate neutre d'ammonium, Comptes Rendus Academie des Science de Paris - Serie C, 276, 947-950, 1973.

Choi, M. Y. and Chan, C. K.: The effects of organic species on the hygroscopic behaviors of inorganic aerosols, Environ. Sci. Technol., 36, 2422-2428, 2002.

Cruz, C. N. and Pandis, S. N.: Deliquescence and hygroscopic growth of mixed inorganic-organic atmospheric aerosol, Environ. Sci. Technol., 34, 4313-4319, 2000.

Cziczo, D. J. and Abbatt, J. P. D.: Deliquescence, efflorescence and supercooling of ammonium sulfate aerosols at low temperature: implications for cirrus cloud formation and aerosol phase in the atmosphere, J. Geophys. Res., 104, 13 781-13 790, 1999.

Cziczo, D. J. and Abbatt, J. P. D.: Infrared observations of the response of $\mathrm{NaCl}, \mathrm{MgCl}_{2}, \mathrm{NH}_{4} \mathrm{HSO}_{4}$ and $\mathrm{NH}_{4} \mathrm{NO}_{3}$ aerosols to changes in relative humidity from 298 to $238 \mathrm{~K}$, J. Phys. Chem. A, 104, 2038-2047, 2000.

Hameri, K., Charlson, R. J., and Hansson, H.-C.: Hygroscopic properties of mixed ammonium sulfate and carboxylic acid particles, Am. Inst. Chem. Eng. J., 48, 1309-1316, 2002.

Han, J. H. and Martin, S. T.: Heterogeneous nucleation of the efflorescence of $\left(\mathrm{NH}_{4}\right)_{2} \mathrm{SO}_{4}$ particles internally mixed with $\mathrm{Al}_{2} \mathrm{O}_{3}$, $\mathrm{TiO}_{2}$, and $\mathrm{ZrO}_{2}$, J. Geophys. Res., 104, 3543-3553, 1999.

$\mathrm{Hu}$, J. H. and Abbatt, J. P. D.: Reaction probabilities for $\mathrm{N}_{2} \mathrm{O}_{5}$ hydrolysis on sulfuric acid and ammonium sulfate aerosols at room temperature, J. Phys. Chem. A, 101, 871-878, 1997.

IPCC (2001), Climate Change 2001: The Science of Climate Change, Intergovernmental Panel on Climate Change, Houghton, J. T., Meira Filho, L. G., Callander, B. A., et al., Cambridge, Cambridge University Press.

Kane, S. M., Claoz, F., and Leu, M.-T.: Heterogeneous uptake of gaseous $\mathrm{N}_{2} \mathrm{O}_{5}$ by $\left(\mathrm{NH}_{4}\right)_{2} \mathrm{SO}_{4}, \mathrm{NH}_{4} \mathrm{HSO}_{4}$ and $\mathrm{H}_{2} \mathrm{SO}_{4}$ aerosols, J. Phys. Chem. A, 105, 6465-6470, 2001.

Lightstone, J. M., Onasch, T. B., and Imre, D.: Deliquescence, efflorescence and water activity in ammonium nitrate and mixed ammonium nitrate/succinic acid microparticles, J. Phys. Chem. A, 104, 9337-9346, 2000.

Marcolli, C., Luo, B., and Peter, T.: Mixing of the organic aerosol fractions: Liquids as the thermodynamically stable phases, J. Phys. Chem. A, 108, 2216-2224, 2004.

Martin, S. T., Schlenker, J., Chelf, J. H., and Duckworth, O. W.: Structure-activity relationships of mineral dusts as heterogeneous nuclei for ammonium sulfate crystallization from supersaturated aqueous solutions, Environ. Sci. Technol., 35, 1624-1629, 2001. 
Mozurekewich, M. and Calvert, J. G.: Reaction probability of $\mathrm{N}_{2} \mathrm{O}_{5}$ on aqueous aerosols, J. Geophys. Res. A, 93, 15 889-15 896, 1988.

Narukawa, M., Kawamura, K., Li, S.-M., and Botttenheim, J. W.: Dicarboxylic acids in the arctic aerosols and snowpacks collected during ALERT 2000, Atmos. Environ., 36, 2491-2499, 2002.

Narukawa, M., Kawamura, K., Takeuchi, N., and Nakajima, T.: Distribution of dicarboxylic acids and carbon isotopic compositions in aerosols from 1997 Indonesian forest fires, Geophys. Res. Lett., 26, 3101-3104, 1999.

Onasch, T. B., Siefert, R. L., Brooks, S. D., Prenni, A. J., Murray, B., Wilson, M. A., and Tolbert, M. A.: Infrared spectroscopic study of the deliquescence and efflorescence of ammonium sulfate aerosol as a function of temperature, J. Geophys. Res., 104, 21 317-21 326, 1999.

Parsons, M. T., Mak, J., Lipetz, S. J., and Bertram, A. K.: Deliquescence of malonic, succinic, glutaric and adipic acid particles, J. Geophys. Res., 109, D06212, doi: 10.1029/2003JD004075, 2004.

Prenni, A. J., DeMott, P. J., and Kreidenweis, D. C.: Water uptake of internally mixed particles containing ammonium sulfate and dicarboxylic acids, Atmos. Environ., 37, 4243-4251, 2003.

Prenni, A. J., DeMott, P. J., Kreidenweis, S. M., Sherman, D. E., Russell, L. M., and Ming, Y.: The effects of low molecular weight dicarboxylic acids on cloud formation, J. Phys. Chem. A, 105, 11240-11248, 2001.

Ravishankara, A. R.: Heterogeneous and multiphase chemistry in the troposphere, Science, 276, 1058-1065, 1997.
Rohrl, A. and Lammel, G.: Low molecular weight dicarboxylic acids: seasonal and air mass characteristics, Environ. Sci. Technol., 35, 95-101, 2001.

Schlenker, J. C., Malinowski, A., Martin, S. T., Hung, H. M., and Rudich, Y.: Crystals Formed at $293 \mathrm{~K}$ by Aqueous SulfateNitrate-Ammonium-Proton Aerosol Particles, J. Phys. Chem., accepted, August 2004

Seinfeld, J. H. and Pandis, S. N.: Atmospheric Chemistry and Physics: From air pollution to climate change, New York, John Wiley \& Sons Inc., 1998.

Thornton, J., Braban, C. F., and Abbatt, J. P. D.: $\mathrm{N}_{2} \mathrm{O}_{5}$ hydrolysis on sub-micron organic aerosols: The effect of relative humidity, particle phase, and particle size, Phys. Chem. Chem. Phys., 5, 4593-4603, 2003.

Wise, M. E., Surratt, J. D., Curtis, D. B., Shilling, J. E., and Tolbert, M. A.: Hygroscopic growth of ammonium sulfate/dicarboxylic acids, J. Geophys. Res., 108, Art No. 4638, doi:10,1029/2003JD003775, 2003.

$\mathrm{Xu}$, J., Imre, D., McGraw, R., and Tang, I.: Ammonium sulfate: equilibrium and metastability phase diagrams from 40 to $-50^{\circ} \mathrm{C}$, J. Phys. Chem. B, 102, 7462-7469, 1998.

Yao, X., Fang, M., and Chan, C. K.: Size distributions and formation of dicarboxylic acids in atmospheric particles, Atmos. Environ., 36, 2099-2109, 2002. 